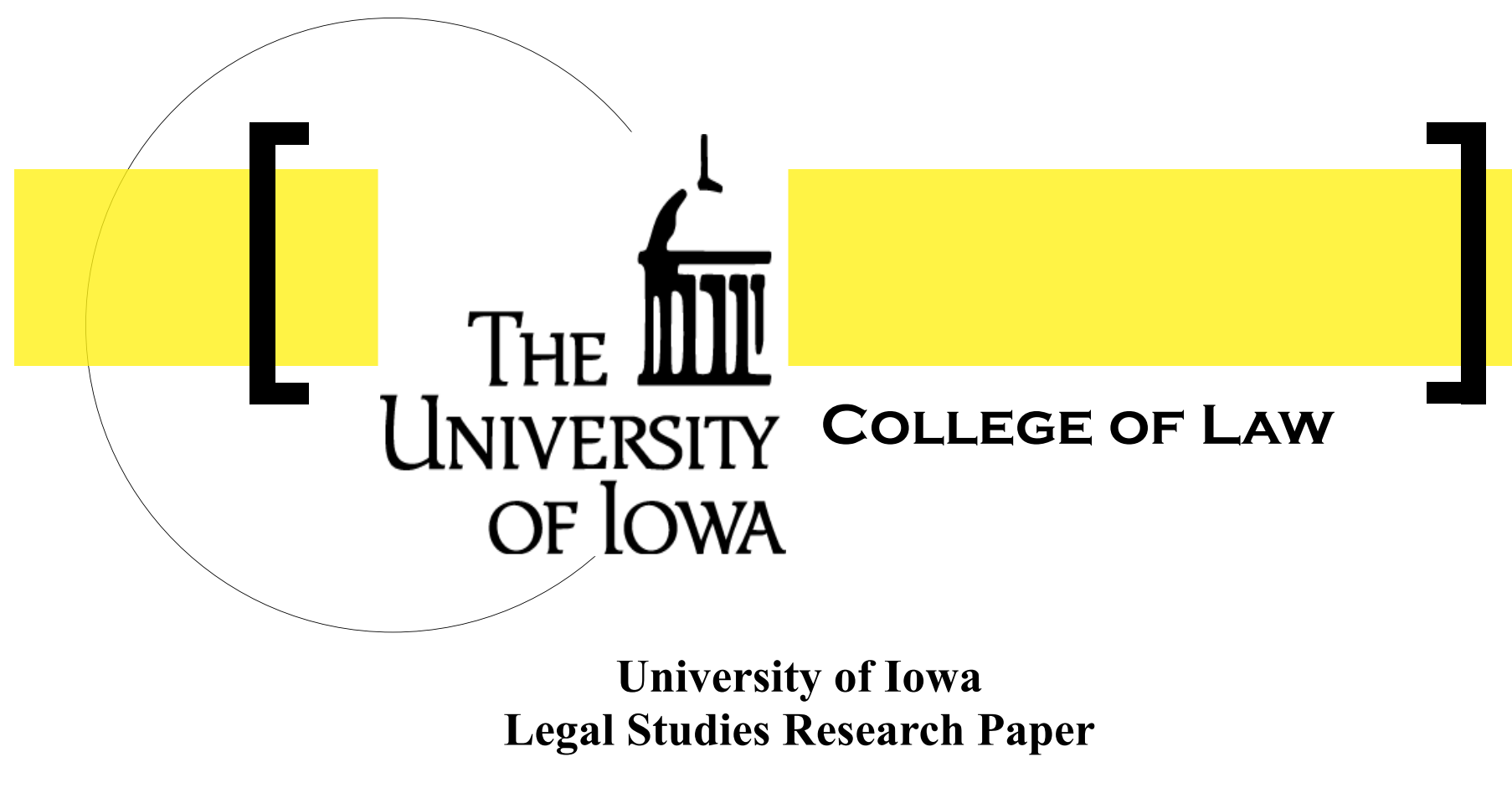

Number 15-22

October, 2015

\title{
EXPERIENTIAL TEACHING IN THEORY AND PRACTICE: AN ANNOTATED INTERNATIONAL BUSINESS TRANSACTIONS SYLLABUS
}

\author{
Maya Steinitz \\ University of Iowa, College of Law \\ $\&$ \\ Orit Shalomson \\ Independent \\ $\&$ \\ Naomi Steinitz-Edelman \\ Independent
}


INTRODUCTION

In 2013 we set out to re-develop a 3-credit International Business Transactions (IBT) course that takes a deeply experiential approach. We applied experiential pedagogical methodologies-developed initially to train Israeli air force pilots and later adapted to medical training and grounded in theoretical and empirical education research-to serve in a traditional IBT course. The goal was not only to develop legal skills such as negotiation, contract drafting, and client counseling but more importantly to impart knowledge including legal doctrine, legal theory, and policy considerations through the use of a series of structured, in-class experiences. It is a core precept of experiential learning ("EL") theory that different learners respond best to different combinations of learning by doing, watching, thinking and feeling whether they are acquiring skills or knowledge. (And, indeed, it was particularly gratifying to witness how students who often resist discussions of theory and policy craved it once they experienced their value).

Given that in our experience some of the resistance to $E L$ stems from mere unfamiliarity with it, from a belief that an inordinate amount of work would be required to incorporate such teaching methods into existing courses, and/or from a belief that EL is appropriate only to teach skills but not knowledge, we decided to apply a principle of "show, don't tell"-i.e. to provide an example of

1. Professor of Law at the University of Iowa College of Law. A full bio available at http://www.law.uiowa.edu/faculty/mayasteinitz.php. Professor Steinitz can be contacted at maya-steinitz@uiowa.edu.

2. Founder and Executive Director, Simulation and Training Center, Ono Academic College, Israel. Associate Professor of Interpersonal Communication, Faculty of Health Professions, Ono academic College. Training and Development Instructor, Faculties of Law and of Business Administration, Ono Academic College. PhD, Sackler Faculty of Medicine, Department of Medical Education, Tel Aviv University. Dr. Shalomson can be contacted at Orit.shalomson@gmail.com.

3. BA, Hebrew University of Jerusalem; MA, Hebrew university of Jerusalem. Instructional designer, training developer, organizational consultant \& trainer. Adjunct professor at the Ono Academic College, teaching interpersonal communication skill using experiential learning methods. Has past experience in conducting simulation-based training to caregivers in the national healthcare systems. Ms. Steinitz - Edelman can be contacted at n.steinitz@gmail.com. 
a traditional IBT course into which EL has been incorporated. In so doing, we hope to contribute to the discussion on EL what we have learned experimenting with teaching IBT experientially by providing an annotated syllabus in the hope that other law professors would find it helpful to see how EL has been implemented in a traditional law course. Specifically, we aim to (i) illustrate some of the ways in which EL can be incorporated into an existing, traditional (doctrinal) course and; (ii) illustrate how EL can be used not only to develop skills but also to impart knowledge; (iii) and in so doing address some common objections to deploying EL approaches in 'regular' law school classrooms. The annotations provide information on matters such as available EL methodologies and the andragogical principles underlying certain course-design choices. (Andragogy being the science and practice of educating adult learners). The information is meant to be illustrative not exhaustive and the goal is not here to provide a full scholarly treatment. Given our modest goals, we only provide annotations to a few select experiences-those that we regard the basic building blocks of EL or of this particular course-since our purpose is to demonstrate how to incorporate EL into a traditional course, not to provide a full course plan.

The syllabus provided herein has been modified from the original used in class, and is pre-sented in a somewhat abstract form (e.g., the reading assignments are omitted) for four reasons. One, is that it reflects two versions in which the revised course has now been taught: one is a traditional semester-long 3-credit format and the other in a one-week one-credit format. Second, is that the course and the syllabus are works-in-progress. For example, a key conclusion from the first two runs at the experiential approach is that "flipping" the class room-i.e., in our case assigning pretaped lectures to be viewed at home before classwould resolve the tension between the class-room time-consuming experiential approach, on the one hand, and coverage requirements, on the other. Third, we want to emphasize that professors need not abandon, or even significantly revise syllabi they have perfected over the course of years. They can simply add or substitute some of the Socratic discussions with one or more experiences. Fourth, due to time constraints, we ended up using only some of the experiences we developed. However, given their innovative nature, we are including them here (and looking forward to using them with our students in the future) by mentioning them in the course outline. In that vein, it is important to note that we recommend transition into $\mathrm{EL}$ gradually. For example, a single experience at the beginning of a course or at the conclusion of a subject can transform the course. 


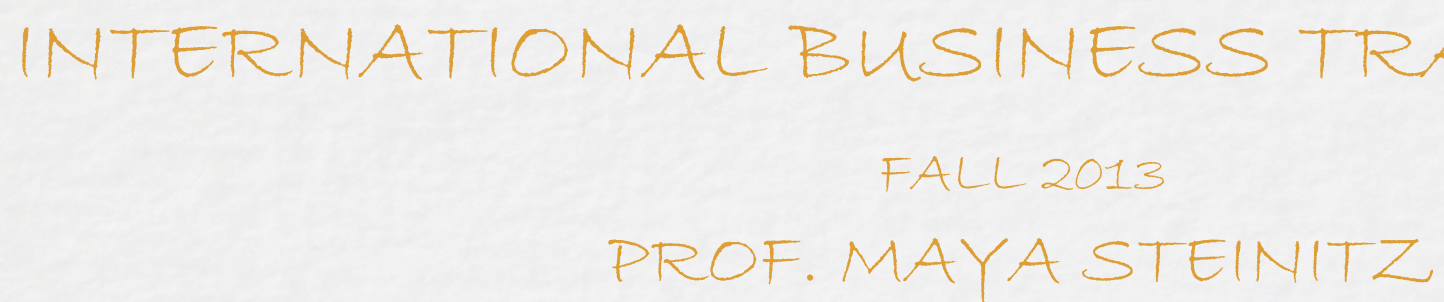

By email appointment

The design of this course is premised on the andragogical theory of David Kolb (Andragogy is the study of adult learning). According to Kolb and his progeny, adults learning can be graphed on two axes: one, is the axis of how knowledge is perceived by doing vs. watching. The other, is how knowledge is processed through thinking vs. feeling. Each learner can be represented by a dot on the graph namely we all learn by doing, watching, thinking and feeling however, the emphasis on each differs. (Kolb, DA (1984) Experiential learning: Experience as the source of learning and development. New Jersey: Prentice-Hall). We therefore believe that a welldesigned course should appeal to all the different learners in the class room.

\section{SYLLABUS}

\section{Course Description:}

I. The course surveys the key areas of international business law which impact cross-border transactions. These are noted below in blue font. They are:

1) The basic documentary transaction;

2) International investment law;

3) International trade regulation.

II. The course also pursues a number of themes that are interwoven throughout the aforementioned doctrinal areas. These are also noted in blue font below and they include, but are not limited to:

1) Sources of international law;

2) Comparative law;

3) Issues in trans-lawyering e.g., ethics and cultural differences (general and legal);

4) International conflict of laws.

III. The course introduces and provides exposure to a wide verity of lawyering skills. These are noted in
EL requires two types of conceptual and practical adjustments: One, is in how to use classroom time; the other is in how to use out-of-class time. Specifically, out-of-class time is best used to provide students with their first encounter with the subject matter (e.g., the Convention on the International Sale of Goods). This can be done, for example, through reading or through watching pre-taped lectures. In-class time is used for internalizing the knowledge and better grasping its various dimensions through acting, observing, and reflecting back on the experience. For example, through simulation followed by debriefing (discussed here). Note: for the optimal user experiencectopeni this Pdocumentilin Aatobettps://ssrn.com/abstract=2665206 
green font below. The various types of transactions we will explore are noted in red font. Prerequisites: There are no pre-requisites for this course. In particular, there is no need for background in business or business law.

Required Texts:

1. A Reading Packet is available on Icon.

2. Certain international instruments, such as the Convention on the International Sale of Goods, will be assigned throughout. These are available online.

3. Simulations instructions. All simulation materials will be distributed in class prior to the simulation.

Additional reading may be assigned from time to time as the course progresses.

Recommended Texts:

- We may be making reference to current events in class. It is therefore recommended that you keep up-to-date with at least one of the following: the New York Times (especially the business section); the Financial Times, and the Wall Street Journal.

- For those who have not taken a basic course in international law it is strongly recommended that you read chapters 1 and 2 Vaughan Lowe, International Law (Clarendon Law). 
- Tina L. Stark, Drafting Contracts: How and Why Lawyers Do What They Do (2007).

- Roger Fisher, William Ury \& Bruce Patton, Getting To Yes: Negotiating Agreements Without Giving In (2011).

- Corchran et al., the Counselor-atLaw: A collaborative Approach to Client Interviewing and Counseling.

Requirements and Evaluation:

Requirements:

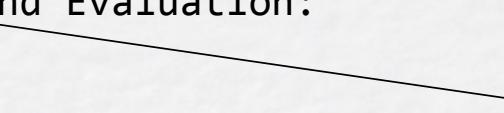

- Attendance: You will be expected to attend class regularly and to have read the assigned material. If you cannot attend a session please email me in advance. Any student who misses more than 4 classes (a 3 hour session counts as 2 classes) will be dropped from the class or subject to another sanction, at my discretion.

- Written assignments: There are a number of written assignments throughout the semester. Timely submission is a prerequisite for completing the course and failure to submit all assignments in time will result in grade reduction.

Given that EL was new to both the students and the teacher we chose a combination of evaluation methods that were both experiential and 'traditional'. We did so specifically in recognition of the fact that students may be overwhelmed by a new way of learning and anxious about evaluation methods they have never encountered before.
Evaluation:

1. Participation - 30\% Percent. Participation will be evaluated by quality rather than quantity. Factors will include, inter alia, the level of preparation (where tasks are circulated in advance), the ability to incorporate and apply the readings to the handson exercises, quality of ungraded written assignments such as observation sheets and journal assignment, and
When the teaching method shifts toward integrating EL, the evaluation methods need to reflect that shift as well. At the most basic level, in order to evaluate the acquisition of a skill one should evaluate a situation wherein the student is required to exhibit the skill. On a deeper level, just like knowledge is best acquired through combinations of doing, watching, thinking and feeling, knowledge is best displayed for evaluation purposes when the students are given different modalities of exhibiting the knowledge they have acquired. For example, requiring a student to draft a choice of law clause may be the best way to learn whether and what the student learned about choice of law. By the same token, requiring a student to counsel a "client" about different possible ways of conducing foreign direct investment (FDI) may be the best way for the student to exhibit, and the teacher to observe, the student's grasp of FDI. It is also gratifying to see that the students walk away with a real inner sense of what they know as well as where they still have gaps. 
insightfulness.

2 . Clause drafting exercises - $30 \%$ $(2 \times 15 \%)$. There will be three drafting exercises throughout the semester. The first will not be graded. The second and the third will each be graded and assigned 15\% each.

3. Client Counseling Simulation $40 \%$. Each student will simulate client counseling for 20 minutes. (Prof. Steinitz will be the 'client'). Knowledge of the law, ability to apply the law to the facts, ability to think on your feet, and the various communication skills called upon in client counseling will be evaluated. The

In recognition of the fact that the novelty of the teaching methods may create anxiety among students who are exposed to it for the first time, and because students are expected to visibly engage in trial-and-error in the presence of peers and the teacher, "student safety" requires transparency. This means going into great detail in explaining the teaching methodologies that will be used, the evaluation methods, course progression and more. We do this both at the outset of the course as a whole (already pre-shadowed by this elaborate syllabus the students receive in advance and the course description provided to students when they select their courses) as well as at the outset of each session. Setting the stage properly is essential for success. client counseling exercise will be handed out at the last session so that students will have time to prepare. The counseling sessions will take place during the regular scheduled exam time.

Note, the following schedule, and content, is subject to change.

Substantive knowledge appears in blue fonts, skills appear in green fonts and transaction type in red fonts.

1. Course Overview and Introduction Goals :

(1) Understanding the content, structure and learning methodologies of the course.

(2) Understanding the sources of international law and the interaction between them and U.S. law.

(3) Introducing the Convention on the International Sale of Goods (CISG). Reading:

(1) $[x x x]$

Viewing:

(1) [taped lecture]
As an example of "setting the stage," here the professor explains to the students the principles that underlay the cycle of action and reflection which is at the heart of all EL. Reflection often takes the form of "debriefing": a structured, mediated post-experience analysis (done, inter alia, by relating the experience back to the assigned reading). See Fanning R.M., Gaba D.M., Simulation in health care; 2007; 2:1.

Another form of reflection is the "feedback": feedback is advice provided with the intention of improving or advancing one's abilities or knowledge. In addition, whereas in debriefing the professor is eliciting the reaction from students, with only minimal reaction provided directly by the professor, in a feedback session most of the reaction is the authoritative input of the professor with only minimal input from the students.

See, Ovando M.N., (1994) Constructive feedback: A key to successful teaching and learning. International Journal of Educational Management, Vol. 8 Iss: 6, pp. 19 - 22. Reflection, whether via debriefing or feedback, is understood to be the most important part of an experience (and if done poorly can harm the student). As a rule of thumb, the debriefing/ feedback should take twice as long as the experience itself. 
Here, we used a "jumping into the water" experience. The students were given opposing negotiation positions and were tasked with the goal of reaching a term sheet on a basic sale of goods transaction. (Click here to view the instructions the students received, as an example).

Andragogy teaches us that adults learn best when they are confronted with a problem they need to solve. (Knowles, M. S. (1975). Self-directed learning: A guide for learners and teachers. Englewood Cliffs: Prentice Hall/Cambridge). We have therefore created for them an opportunity to reach on their own the conclusions that (i) international sale of goods transactions are characterized by unique challenges (e.g., trans-oceanic shipment, different currencies) and; (ii) that they do not yet know how to solve these challenges and that therefore the knowledge, including theory and policy considerations, offered in the rest of the unit is of practical value. In addition, this kind of role play achieves transparency by allowing the students to experience... experiential learning.

(THE DOCUMENTARY TRANSACTION)

2. Introducing the Documentary Sale of Goods Transaction (Safe Babies, Inc. Role Play)

Goals :

(1) Understanding the

characteristic challenges and features of the 'documentary transaction.'

(2) Getting introduced to negotiation dynamics and theory.

3 . The Nuts and Bolts of the Documentary Sales Contract (A Human Puzzle)

Goals :

(1) Understanding the 'anatomy' of the documentary transaction including introduction to the Bill of Lading, Letter of Credit, and Bill of Exchange.

(2) Understanding commercial terms primarily, FOB, FAS, C\&F, CIF

(3) Becoming acquainted with the

ICC Incoterms.

(4) Analyzing the business side of

a transaction.

4. Conflict of Laws \& Force Majeure (Safe Babies, Inc. Client Counseling

"Fish-bowl" Simulation)

Goals:

(1) understanding the basics of international conflict of laws.

(2) Understanding force majeure in the IBT context.

(3) Introducing the UNIDROIT Principles.

(4) Client counseling.

(5) Comparing legal norms and

systems.
Role play (often erroneously referred to as a simulation) involves two or more students who play different roles in an interactive situation. For example, students may play the roles of two attorneys negotiating an international business transaction. The goal is defined for the students but the process is not. The key benefit of the role play is that it allows application of knowledge. Role play also allows "doers" and "watchers" to best absorb knowledge while acquiring a skill. A simulation, conversely, involves a professional actor who plays out a script $s /$ he was trained to preform and the student is required to engage in real time with the actor. [Gaba, D. M. (2004) The future vision of simulation in health care. Qual Saf Health Care, 13(1): i2-i10.] 
5. Financing - Letters of Credit ("Fishbowl" Client Counseling Simulation)

Goals:

(1) Understanding the purpose, characteristics and principles of letters of credit including (a) the independence principle and; (b) the strict compliance rule;

(2) Understanding enjoining payment of letters of credit due to fraud. deals.

(3) Analyzing and diagraming

(4) Effectively explaining difficult and/or legal concepts to

The professor will want to strike a balance between repeating a methodology more than once to allow students to get comfortable with it, on the one hand, but not to repeat it so much that the students get bored, on the other hand. However, the sequence of action and reflection, it should be noted, is the bedrock of EL taking different guises in different methodologies but present in all. clients.

(5) Learning by actively observing other attorneys.

6. Financing - Standby Letters of Credit (Presenting Case-law to Supervisors at Steinitz \& Associates "Fishbowl" Role Play)

Goals:

(1) Understanding the characteristics and uses of the standby letter of credit and contrasting it with the letter of credit.

(2) Understanding the fraud exception to the independence principle. deals.

(3) Analyzing and diagraming

(4) Effectively communicating research findings and case analysis to a supervisor.
In the classic "fishbowl" the class is broken into two groups: doers and watchers, who engage in so-called active observation. [Fishbowl - Hensley L.G, (2002) Teaching Group Process and Leadership: The Two-Way Fishbowl Model. The Journal for Specialists in Group Work Volume 27, Issue 3, pp. 273-286]

(Click here for an observation sheet). The doers sit in the inner circle and engage in spontaneous, sequential role play. Here, the first student negotiates a Letter of Credit with another student/RA/the professor/actor. At a certain point a second student replaces the first as negotiator, followed by a third, and so forth. (There are different ways of selecting when and how the change occurs: e.g., defined by the professor in advance in terms of duration, or by the students when an impasse is reaches- to give just two examples). Meanwhile, the outer circle of watchers are engaged in active observation. They are given a set of questions to fill out. In the second stage the two groups physically switch places, with the watchers occupying the inner circle and vice versa. The "watchers" then debrief the doers (with or without the professor's facilitation).

"Fishbowl" and the use of observation sheets are also examples of methodologies that can be used in very large classes. 
7. Anatomy of a Contract (Safe Babies, Inc. First Drafting Exercise) Goals:

(1) Understanding the generic structure of contracts.

(2) Understanding the

relationships between business concepts,

legal concepts and contract language.

(3) Working with sample/standard contracts.

(4) Drafting contract clauses.

(5) Teamwork (drafting in pairs).

8. Non-establishment Forms of International Business: Distributorships /Agents (Safe Babies, Inc. Negotiation, Term Sheets and Second Drafting Exercise)

Goals:

(1) Becoming familiar with the non-establishment forms of international business, with an emphasis on distributorships and agencies; being able to compare and contrast the pro's and con's of each and the different legal regimes that may apply to them.

(2) Becoming familiar with term sheets; understand the relationship between oral understandings, terms sheets and a final contract.

(3) Drafting a contract clause.

(4) Marking up (critiquing) contract language.

Candace Lun \& Jeswald W. Salacuse, Negotiation Role Play: MedLee - In Pursuit of a Healthy Joint Venture, available through Harvard's Project on Negotiation at http://www. pon-harvard.edu/shop/medlee-in-pursuit-of-a-healthy-jointventurel
9. Non-establishment Forms: Distributorships /Agents Cont'ed

10. Non-establishment Forms: Joint Ventures and Trans-lawyering ("MedLee" Negotiation Role Play)
Of course, individual feedback was possible because of a small class size. For large classes, if resources are available, a professor may use teaching assistants or legal writing instructors. More generally, however, it is important to note that counter-intuitively many of the EL methodologies can be adapted to very large classes. For example, a role play can be conducted by two students with the rest of the class acting as active observers. Similarly, where a school is willing to invest in some equipment, students can be videotaped and debriefing or feedback can be provided in plenary based on the video. see, Fanning R. M., Gaba D. M., (2007) The role of debriefing in simulation-based learning. Simulation in healthcare, Vol. 2 ,No. $1,1-11$.

This is the first of three drafting exercises. First, students were requested to draft---in pairs, in class - a first draft of a few clauses (preamble, recitals, choice of law, choice of forum) of an international sale of goods contract based on the term sheet they have reached in the first "Safe Babies" role play. Second, each pair was then requested to mark up and provide feedback to another pair on its draft. Third, each pair received the feedback, discussed it, and decided whether and how to revise its draft clauses. Fourth, at home, the students had to draft the final version of the clauses and email to the professor. Feedback was provided in two ways: first, each pair received a markup from the professor and second, in the next session general feedback based on repeated mistakes was provided in plenary. In an example of the connection between EL and knowledge-acquisition (in addition to skillsacquisition) it was striking to see how requiring students to draft choice of law and choice of forum clauses highlighted their mis/understanding of choice of law and forum principles and doctrines. 
Note, this simulation takes $2-3$ hours.

Goals:

(1) Getting a general

understanding of a joint venture.

(2) Understanding overarching

themes in international business

dealings including:

a. Cultural differences;

b. Comparative law and the

major legal systems of the world;

ethics.

c. Transnational legal

(3) Deepening negotiation skills.

(4) Drafting term sheets.

UNIT2 - FOREIGNDIRECTINVESTMENT ("FDI")

AND ECONOMIC DEVELOPMENT

11. Introducing FDI and Economic

Jeswald W. Salacuse, Arun Venkataraman \& Fritz von Carp, Enco, available through Harvard's Project on Negotiation at

http://www.pon.harvard.edu/shop/enco/
Development ("Enco" Client Counseling

Exercise)

\section{Goals:}

(1) Understanding the decision to invest abroad.

(2) Understanding the

characteristics of FDI including:

a. FDI's political nature

and the controversies surrounding it;

b. FDI, human rights, the

environment \& labor protection;

c. Working in developing

countries;

d. Working with foreign

governments;

e. The relationship between

FDI and diplomacy.

(3) The problem of "the

obsolescing bargain.”

(4) Long term deals and 
"relational contracts."

(5) Bargaining in the shadow of transnational dispute resolution.

(6) The (deal) lawyer as trusted advisor.

(7) The (deal) lawyer and

corporate social responsibility (CSR).

12. Introducing FDI and Economic Development - Cont'ed

\section{Overview of International}

\section{Investment Law}

Goals:

(1) Becoming familiar with international investment law, including: Treaties ("BITs"). a. Bilateral Investment

$$
\text { b. The core principles }
$$

of FDI including Non-discrimination, National Treatment.

c. The International

Center for the Settlement of Investment Disputes ("ICSID") regime.

14. Expropriation (U.S. State Dep't and China's Foreign Ministry BIT Negotiation Role Play)

Goal:

(1) Understanding expropriation as the ultimate and paradigmatic threat to a foreign investor.

(2) Further deepening the understanding of BITs and Investor protection.

(3) Understanding features of public international law (the rights and obligations of states).

(4) Stepping into the shoes of the

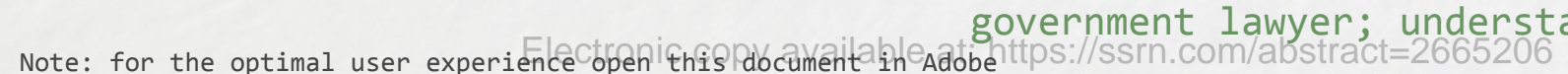


negotiation.

\section{Project Finance (Safe Babies,} Inc. Multi-issue Negotiation)

Goals :

(1) Becoming familiar with the key features of project finance deals.

(2) Understanding relational contracts, renegotiation and stabilization.

(3) Become familiar with multi-issue negotiation and parallel negotiations by multiple teams.

(4) The lawyer as manager and coordinator.

16. Foreign Corrupt Practices Act; The Alien Tort Claims Act and Corporate Social Responsibility (Preparing a Continuing Legal Education (CLE) Presentation)

Goals :

(1) Understanding corporate tort liability abroad and at home; the domestic regulation of American investment overseas.

(2) Becoming familiar with the Corporate Social Responsibility movement / rhetoric. 
17. Introduction to International

Trade Regulation (PACRIM Trade Negotiation Role Play)

Note, this simulation takes

approximately 3.5 hours.

Goals:

(1) Understanding the 'big

picture' politics and macro-economics of trade relations.

(2) Understanding the

multilateral nature of the trade regime.

(3) Multi-party, multi-round negotiations.

\section{Overview of International Trade} Regulation

Goals :

(1) Become familiar with the framework of the trade regulation regime including the WTO, the GATT and the DSB.

19. Overview of International Trade Regulation - Cont'ed

20. Nontariff Barriers (NTBs) and the WTO (Trade Department Role Play Part I)

Goals :

(1) Understanding the concept and the international law of NTBs.

(2) Deepening the understanding of the GATT.

(3) Deepening the understanding of the relationship between international law, diplomacy and domestic politics.

(4) Teamwork and collaboration.

(5) 'Reading' institutions and
Ericka Gray, Negotiation Role Play - Pacrim Dispute, available through Harvard's Project on Negotiation at http://www.pon. harvard.edu/shop/pacrim-dispute/ 
21. Subsidies and Countervailing Duties (Trade Department Role Play Part II)

Goals:

(1) Understanding the concept and the international law of subsidies and CVD.

(2) Deepening the understanding of the GATT.

(3) Deepening the understanding of the relationship between

international law, diplomacy and domestic politics.

(4) Teamwork and collaboration.

(5) 'Reading' institutions and

players.

22. Antidumping Duties (Trade Department Role Play Part III)

Goals:

(1) Understanding the concept and the international law of antidumping.

(2) Deepening the understanding of the GATT.

(3) Deepening the understanding of the relationship between (public) international law, diplomacy and domestic politics.

(4) Teamwork and collaboration.

(5) 'Reading' institutions and

players.

23. Drafting a Clause in a Trade Treaty

Third drafting exercise. 
If you find this short piece useful you may also wish to view a short youtube video in which Orit and Maya walk through the recently launched Simulation and Training Center at the Ono Academic College, Israel, and discuss how high-quality experiential learning, based on adragogical studies, can be scaled up to provide meaningful experiences to high volumes of students. The video is elegantly titled "Prof. Maya Steinitz and Dr. Orit Shalomson in a Conversation About Providing High Quality, High Volume Experiential Learning in Law School" and available here. 